Article

\title{
Iron-Mediated Homogeneous ICAR ATRP of Methyl Methacrylate under ppm Level Organometallic Catalyst Iron(III) Acetylacetonate
}

\author{
Jian Wu, Xiaowu Jiang, Lifen Zhang *, Zhenping Cheng * and Xiulin Zhu \\ Suzhou Key Laboratory of Macromolecular Design and Precision Synthesis, Jiangsu Key Laboratory of \\ Advanced Functional Polymer Design and Application, Department of Polymer Science and Engineering, \\ College of Chemistry, Chemical Engineering and Materials Science, Soochow University, Suzhou 215123, China; \\ wujian_suda@163.com (J.W.); jiang_xiao_wu@163.com (X.J.); xlzhu@suda.edu.cn (X.Z.) \\ * Correspondence: zhanglifen@suda.edu.cn (L.Z.); chengzhenping@suda.edu.cn (Z.C.); \\ Tel.: +86-512-6588-2056 (L.Z.); +86-512-6588-0727 (Z.C.); Fax: +86-512-65882787 (Z.C.)
}

Academic Editor: Nicolay V. Tsarevsky

Received: 20 December 2015; Accepted: 19 January 2016; Published: 26 January 2016

\begin{abstract}
Atom Transfer Radical Polymerization (ATRP) is an important polymerization process in polymer synthesis. However, a typical ATRP system has some drawbacks. For example, it needs a large amount of transition metal catalyst, and it is difficult or expensive to remove the metal catalyst residue in products. In order to reduce the amount of catalyst and considering good biocompatibility and low toxicity of the iron catalyst, in this work, we developed a homogeneous polymerization system of initiators for continuous activator regeneration ATRP (ICAR ATRP) with just a ppm level of iron catalyst. Herein, we used oil-soluble iron (III) acetylacetonate $\left(\mathrm{Fe}(\mathrm{acac})_{3}\right)$ as the organometallic catalyst, 1,1'-azobis (cyclohexanecarbonitrile) (ACHN) with longer half-life period as the thermal initiator, ethyl 2-bromophenylacetate (EBPA) as the initiator, triphenylphosphine $\left(\mathrm{PPh}_{3}\right)$ as the ligand, toluene as the solvent and methyl methacrylate (MMA) as the model monomer. The factors related with the polymerization system, such as concentration of $\mathrm{Fe}(\mathrm{acac})_{3}$ and $\mathrm{ACHN}$ and polymerization kinetics, were investigated in detail at $90^{\circ} \mathrm{C}$. It was found that a polymer with an acceptable molecular weight distribution $\left(M_{\mathrm{w}} / M_{\mathrm{n}}=1.43\right.$ at $45.9 \%$ of monomer conversion) could be obtained even with 1 ppm of Fe(acac) $)_{3}$, making it needless to remove the residual metal in the resultant polymers, which makes such an ICAR ATRP process much more industrially attractive. The "living" features of this polymerization system were further confirmed by chain-extension experiment.
\end{abstract}

Keywords: ICAR ATRP; organometallic catalyst; Fe(acac) 3

\section{Introduction}

Reversible deactivation radical polymerization (RDRP) [1-7] including initiator-transfer agent-terminator (Iniferter) [8-11], nitroxide-mediated polymerization (NMP) [12-18], atom transfer radical polymerization (ATRP) or metal-catalyzed living radical polymerization [19-43] and reversible addition-fragmentation chain transfer polymerization (RAFT) [44-55] has been used to design and synthesize various polymeric structure and architectures extensively. Among those methods, ATRP is the most widely used method and has been used to produce different topological polymers, such as star, brush, block and hyperbranched polymers [56-59]. On the other hand, it is well known that some shortages of ATRP also exists, such as the large amount of metal catalyst residues in products. In 2007, Matyjaszewski's group found that in the polymerization systems (e.g., MMA/EBPA/Cu(II)/tris(2-pyridylmethyl)amine (TPMA)/azobis(isobutyronitrile) (AIBN)), reducing the amount of catalyst $(<50 \mathrm{ppm})$ while increasing the amount of traditional radical initiator (such 
as $\left.[\mathrm{AIBN}]_{0} /[\mathrm{Cu}]_{0}>10\right)$ could control the polymerization systems quite well. They called this method initiators for continuous activator regeneration atom transfer radical polymerization (ICAR ATRP) [60-65]. Actually, the most important advantage of ICAR ATRP [60-65] over normal ATRP is that the desired amount of catalyst is significantly reduced because the continuously produced free radicals can reduce the high oxidation transition metal complexes so that the catalyst can remain active during the polymerization process.

There have been many catalysts which can be used in ICAR ATRP, such as Cu [66,67], Ru [68], and Fe $[69,70]$. However, most of them are poisonous and expensive. Therefore the application of many catalysts is limited in large-scale industrial production especially in the field of biomedical and electrical materials. Because of the low toxicity and good biocompatibility of iron salt, the iron catalytic systems are more and more popular in academic research community since the Sawamoto's group reported the controlled polymerization system catalyzed by $\mathrm{FeCl}_{2} / \mathrm{PPh}_{3}$ [71]. The common ligands for iron salt are nitrogen-containing ligands [72-79], phosphorus-containing ligands [80-88], organic acids [89-93] and polyethylene glycols [94]. Furthermore, the application of many catalysts (e.g., inorganic transition metal catalysts) is limited because of their solubility in oil-soluble reaction systems. In 2014, an organic transition metal catalyst iron(III) acetylacetonate ( $\mathrm{Fe}(\mathrm{acac})_{3}$ ) was employed as the catalyst of activators generated by electron transfer for ATRP (AGET ATRP) of methyl methacrylate (MMA) using ascorbic acid (AsAc) as reducing agent for the first time [95]. However, the concentration of iron catalyst is relatively high and the polymerization system was heterogeneous due to the use of polar reducing agent ascorbic acid.

Based on these problems, we try to use an organic iron salt as the catalyst to set up a homogeneous iron-mediated ICAR ATRP suitable for oil-soluble polymerization system, which can be controllable when the amount of catalyst is reduced to ppm level. It should be noted that azobisisobutyronitrile (AIBN) is used as the thermal initiator in an ICAR ATRP system usually. However, we notice that $1,1^{\prime}$-azobis cyclohexanecarbonitrile (ACHN) with a longer half-life period $\left(10 \mathrm{~h}\right.$ at $\left.88^{\circ} \mathrm{C}\right)$ [96] is a more thermally stable azo-initiator than AIBN $\left(10 \mathrm{~h}\right.$ at $\left.65^{\circ} \mathrm{C}\right)$, which facilitates to conduct ICAR ATRP at a relatively higher temperature. Herein, we used ACHN as the thermal initiator to establish an iron-mediated homogeneous ICAR ATRP system using oil-soluble $\mathrm{Fe}(\mathrm{acac})_{3}$ as the organometallic catalyst and $\mathrm{PPh}_{3}$ as the ligand. This polymerization system provided an efficient homogeneous polymerization of MMA under ppm level of iron catalyst at $90^{\circ} \mathrm{C}$.

\section{Experimental Section}

\subsection{Materials}

The monomer, methyl methacrylate (MMA, +99\%), was purchased from Shanghai Chemical Reagents Co. Ltd. (Shanghai, China). It was purified via removing the inhibitor by passing through a short neutral alumina column before use. Azobis(isobutyronitrile) (AIBN), which was purchased from Shanghai Chemical Reagents Co. Ltd. and 1,1'-azobis cyclohexanecarbonitrile (ACHN, 98\%, Aldrich, Shanghai, China) were purified by recrystallization from ethanol. The following materials were used as received. These materials are ethyl 2-bromophenylacetate (EBPA, 97\%) purchased from J\&K Scientific Ltd. (Beijing, China), triphenylphosphine ( $\mathrm{PPh}_{3}, 98 \%$ ) purchased from Energy chemical (Shanghai, China), ethyl 2-bromo-2-methylpropionate (EBiB, 98\%) purchased from Acrso, tetrahydrofuran (THF, analytical reagent) purchased from Nanjing Chemical Reagent Co. Ltd. (Nanjing, China), toluene (analytical reagent) purchased from Chinasun Specialty Products Co. Ltd. (Changshu, China) and iron(III) acetylacetonate (Fe(acac) 3 , 99.95\%) purchased from Aldrich (Shanghai, China).

\subsection{General Procedure for ICAR ATRP of MMA}

A typical solution polymerization procedure for the molar ratio of $[\mathrm{MMA}]_{0}:[\mathrm{EBPA}]_{0}:\left[\mathrm{Fe}(\mathrm{acac})_{3}\right]_{0}:\left[\mathrm{PPh}_{3}\right]_{0}:[\mathrm{ACHN}]_{0}=200: 1: 0.03: 0.3: 1$ is as follows. A homogeneous mixture was obtained by adding $\mathrm{Fe}(\mathrm{acac})_{3}(0.51 \mathrm{mg}), \mathrm{PPh}_{3}(3.7 \mathrm{mg})$, MMA $(1.0 \mathrm{~mL}), \mathrm{EBPA}(8.3 \mu \mathrm{L})$, 
ACHN $(8.0 \mathrm{mg})$, toluene $(1.0 \mathrm{~mL})$ and a magnetic stirring bar to a clean ampoule. The mixture was thoroughly bubbled with argon for $20 \mathrm{~min}$ to eliminate the dissolved oxygen in the reaction system, and then flame-sealed; afterwards it was transferred into an oil bath held by a magnetic stirring apparatus at the desired temperature $\left(90^{\circ} \mathrm{C}\right)$ to polymerize under stirring. After the desired polymerization time, the ampoule was cooled by immersing it into iced water. Afterwards, it was opened and the contents were dissolved in THF $(\sim 2 \mathrm{~mL})$, and precipitated into a large amount of methanol $(\sim 200 \mathrm{~mL})$. The polymer obtained by filtration was dried under vacuum until constant weight at $35^{\circ} \mathrm{C}$. The monomer conversion was determined gravimetrically.

\subsection{Chain Extension of PMMA}

A predetermined quantity of PMMA obtained by ICAR ATRP of MMA was added to a clean ampoule, and then the determined quantities of MMA $(0.2 \mathrm{~mL})$, toluene $(1.0 \mathrm{~mL}), \mathrm{Fe}(\mathrm{acac})_{3}, \mathrm{PPh}_{3}$ and ACHN were added. The mixture was thoroughly bubbled with argon for $20 \mathrm{~min}$ to eliminate the dissolved oxygen in the reaction system, and then flame-sealed; afterwards it was transferred into an oil bath held by a thermostat at the desired temperature $\left(90^{\circ} \mathrm{C}\right)$ to polymerize under stirring. The rest of the procedures were the same as that for the polymerization of MMA described above.

\subsection{Characterization}

The number-average molecular weight $\left(M_{n, G P C}\right)$ and molecular weight distribution $\left(M_{\mathrm{w}} / M_{\mathrm{n}}\right)$ values of the resultant polymers were determined by a TOSOH HLC-8320 (Tosoh, Japan) gel permeation chromatograph (GPC) equipped with a refractive-index detector (TOSOH), using TSKgel guardcolumn SuperMP-N $(4.6 \mathrm{~mm} \times 20 \mathrm{~mm})$ and two TSKgel SupermultiporeHZ-N $(4.6 \mathrm{~mm} \times 150 \mathrm{~mm})$ with measurable molecular weight ranging from $5 \times 10^{2}$ to $5 \times 10^{5} \mathrm{~g} / \mathrm{mol}$. THF was used as the eluent at a flow rate of $0.35 \mathrm{~mL} / \mathrm{min}$ and $40^{\circ} \mathrm{C}$. GPC samples were injected using a TOSOH plus autosampler and calibrated with PMMA standards purchased from TOSOH. ${ }^{1} \mathrm{H}$ NMR spectrum of the obtained polymer was recorded on Bruker 300 (Bruker, Coventry, UK) MHz nuclear magnetic resonance (NMR) instrument using DMSO- $\mathrm{d}_{6}$ as the solvent and tetramethylsilane (TMS) as an internal standard at ambient temperature.

\section{Results and Discussion}

\subsection{Effect of Type of Initiator and Solvent on Polymerization of $M M A$}

Firstly, we selected two kinds of ATRP initiators EBPA and EBiB to conduct ICAR ATRP while using ACHN as the thermal initiator. From Table 1, it can be seen that when EBPA (Entries 1, 2 in Table 1) was used as the ATRP initiator, the results prove the better efficiency than EBiB (Entries 3, 4 in Table 1). Specifically, the $M_{n, G P C}$ values are much closer to their corresponding $M_{n, t h}$ ones and narrower molecular weight distributions in the case of EBPA. Therefore, in consideration of significant effect from initiators on polymerization controllability and the facility of the chain-end characterization, the active EBPA, with a phenyl group as the internal standard, was selected as a more appropriate and efficient initiator for the ICAR ATRP of MMA for the following investigation. In addition, in order to study the effect of solvent on the polymerization, we used three different solvents to conduct the polymerization. As is shown in Table 1, the molecular weight distribution of the polymer obtained by using ethanol (Entry 6 in Table 1) as the solvent is broader than using toluene (Entries 1, 2, 5 in Table 1). On the other hand, the polymerization rate using toluene (Entry 5 in Table 1 ) as the solvent is faster than ethyl acetate (Entry 7 in Table 1). Therefore, toluene was used as the solvent for the further investigation. 
Table 1. Effect of different initiators and solvents on initiators for continuous activator regeneration (ICAR) Atom Transfer Radical Polymerization (ATRP) of methyl methacrylate (MMA).

\begin{tabular}{|c|c|c|c|c|c|c|}
\hline Entry & $\mathbf{R}$ & $\mathrm{T}(\mathrm{h})$ & Conv. (\%) & $M_{\mathrm{n}, \mathrm{th}}{ }^{\mathrm{f}}(\mathrm{g} / \mathrm{mol})$ & $M_{\mathrm{n}, \mathrm{GPC}}(\mathrm{g} / \mathrm{mol})$ & $M_{\mathrm{w}} / M_{\mathrm{n}}$ \\
\hline $1^{a}$ & 200:1:0.02:0.3:1 & 3.5 & 64.0 & 12,800 & 17,000 & 1.18 \\
\hline $2^{a}$ & 200:1:0.015:0.3:1 & 3.5 & 54.7 & 10,900 & 15,900 & 1.19 \\
\hline $3^{b}$ & 200:1:0.02:0.3:1 & 1.5 & 43.7 & 8800 & 96,900 & 1.56 \\
\hline $4^{b}$ & 200:1:0.01:0.3:1 & 1.5 & 43.5 & 8700 & 96,500 & 1.46 \\
\hline $5^{c}$ & 200:1:0.02:0.3:1 & 3 & 56.0 & 11,200 & 16,500 & 1.17 \\
\hline $6^{d}$ & 200:1:0.02:0.3:1 & 3 & 53.1 & 10,600 & 24,600 & 1.40 \\
\hline $7^{\mathrm{e}}$ & 200:1:0.02:0.3:1 & 3 & 36.1 & 7200 & 9500 & 1.18 \\
\hline
\end{tabular}

\subsection{Comparison of Using AIBN and ACHN as the Thermal Initiator}

In ICAR ATRP, we usually use AIBN as the azo-initiator; in this work, we used ACHN as the thermal initiator and compared the polymerization behaviors of these two azo-initiators. As shown in Table 2, when the concentration of catalyst is high enough, the molecular weight distributions of the resultant polymers in both azo-initiator cases $\left(M_{\mathrm{w}} / M_{\mathrm{n}} \leqslant 1.30\right)$, but $M_{\mathrm{n}, \mathrm{GPC}}$ values are closer to $M_{n, t h}$ when using ACHN (Entries 1, 2, 4 and 5 in Table 2). However, when the concentration of catalyst is much low $\left(\left[\mathrm{Fe}(\mathrm{acac})_{3}\right]=5 \mathrm{ppm}\right.$, Entry 3 in Table 2$)$, the molecular weight distribution $\left(M_{\mathrm{w}} / M_{\mathrm{n}}=1.42\right.$ in the case of AIBN) is broader than that of using ACHN $\left(M_{\mathrm{w}} / M_{\mathrm{n}}=1.27\right)$ (Entry 6 in Table 2). Therefore, ACHN is more suitable for this polymerization system. It is contributed to the fact that $\mathrm{ACHN}$ has a longer half-life period than AIBN, which facilitates to produce free radicals to reduce Fe(III) species continuously.

Table 2. Effect of type of azo-initiators on ICAR ATRP of MMA.

\begin{tabular}{ccccccc}
\hline Entry & \multicolumn{1}{c}{$\mathbf{R}$} & $\mathbf{T}(\mathbf{h})$ & Conv. $(\mathbf{\%})$ & $\boldsymbol{M}_{\mathbf{n}, \mathbf{t h}}{ }^{\mathrm{c}}(\mathbf{g} / \mathbf{m o l})$ & $\boldsymbol{M}_{\mathbf{n}, \mathbf{G P C}}(\mathrm{g} / \mathbf{m o l})$ & $\boldsymbol{M}_{\mathbf{w}} / \boldsymbol{M}_{\mathbf{n}}$ \\
\hline $1^{\mathrm{a}}$ & $200: 1: 0.02: 0.3: 1$ & 2.5 & 40.8 & 8200 & 14,900 & 1.16 \\
$2^{\mathrm{a}}$ & $200: 1: 0.01: 0.3: 1$ & 2.5 & 37.6 & 7500 & 17,100 & 1.22 \\
$3^{\mathrm{a}}$ & $200: 1: 0.001: 0.3: 1$ & 2 & 58.2 & 11,600 & 24,200 & 1.42 \\
$4^{\mathrm{b}}$ & $200: 1: 0.02: 0.3: 1$ & 3.5 & 64.0 & 12,800 & 17,000 & 1.18 \\
$5^{\mathrm{b}}$ & $200: 1: 0.015: 0.3: 1$ & 3.5 & 54.7 & 10,900 & 15,900 & 1.19 \\
$6^{\mathrm{b}}$ & $200: 1: 0.001: 0.3: 1$ & 3 & 50.1 & 10,000 & 21,100 & 1.27 \\
\hline
\end{tabular}

Polymerization conditions: $\mathrm{R}=[\mathrm{MMA}]_{0}:[\mathrm{EBPA}]_{0}:\left[\mathrm{Fe}(\mathrm{acac})_{3}\right]_{0}:\left[\mathrm{PPh}_{3}\right]_{0}:[\mathrm{RA}]_{0}, V_{\mathrm{MMA}}=1.0 \mathrm{~mL}, V_{\text {toluene }}=1.0 \mathrm{~mL}$;

${ }^{\mathrm{a}} \mathrm{RA}=\mathrm{AIBN}, \mathrm{T}=70{ }^{\circ} \mathrm{C} ;{ }^{\mathrm{b}} \mathrm{RA}=\mathrm{ACHN}, \mathrm{T}=90^{\circ} \mathrm{C} ;{ }^{\mathrm{c}} M_{\mathrm{n}, \mathrm{th}}=\left([\mathrm{M}]_{0} /[\mathrm{I}]_{0}\right) \times M_{\mathrm{n}, \mathrm{MMA}} \times$ conv. $\%$.

\subsection{Effect of Concentration of Iron Catalyst on Polymerization of $M M A$}

From the discussion above, we can see that using ACHN as the azo-initiator can achieve a better control of the polymerization. In order to examine the effect of the concentration of iron catalyst on the polymerization, we keep the same molar ratio of $[\mathrm{MMA}]_{0}:[\mathrm{EBPA}]_{0}:\left[\mathrm{PPh}_{3}\right]_{0}:[\mathrm{ACHN}]_{0}$ to conduct polymerizations under different iron catalyst concentrations. From Table 3, it can be seen that the amount of iron catalyst had a little influence on the reaction rate and as the iron catalyst concentration increased, the molecular weight distributions become narrower, which indicated that the control of the polymerization system is better (Entry 1-6 in Table 3). This is probably because the ability of the catalytic system deactivating chain-growth radical improved as the concentration of iron catalyst increased. Therefore, the free radical concentration decreased and the polymerization system could be well controlled [97]. It is important and worth noting that even though the concentration of iron catalyst decreased to $1 \mathrm{ppm}$ (Entry 9 in Table 3), the polymerization still took place in a controlled manner $\left(M_{\mathrm{w}} / M_{\mathrm{n}}=1.43\right)$, which indicated that this iron-mediated ICAR ATRP system had a high 
catalytic activity. It is worth mentioning that the deviation of $M_{n, t h}$ and $M_{n, G P C}$ increased with the decreasing amount of iron catalyst. This may contribute to the fact that the deactivation reaction is less controlled in the beginning of ATRP (in particular due to the lack of halide in Fe(acac) $)_{3}$ ), but the situation subsequently improves toward moderate and high degrees of monomer conversion.

Table 3. Effect of the concentration of the catalyst on ICAR ATRP of MMA

\begin{tabular}{ccccccc}
\hline Entry & Catalyst Concentration (ppm) & $\mathbf{T}$ (h) & Conv. $\mathbf{( \% )}$ & $\boldsymbol{M}_{\mathbf{n}, \mathbf{t h}}{ }^{\mathbf{a}}(\mathbf{g} / \mathbf{m o l})$ & $\boldsymbol{M}_{\mathbf{n}, \mathbf{G P C}}(\mathbf{g} / \mathbf{m o l})$ & $\boldsymbol{M}_{\mathbf{w}} / \boldsymbol{M}_{\mathbf{n}}$ \\
\hline 1 & 150 & 2 & 27.4 & 5500 & 10,600 & 1.17 \\
2 & 150 & 4 & 66.5 & 13,300 & 19,500 & 1.13 \\
3 & 100 & 2 & 41.0 & 8200 & 15,700 & 1.20 \\
4 & 100 & 4 & 68.0 & 13,600 & 19,000 & 1.14 \\
5 & 75 & 2 & 30.6 & 7100 & 11,800 & 1.23 \\
6 & 75 & 4 & 63.0 & 12,600 & 17,400 & 1.18 \\
7 & 5 & 3 & 50.1 & 10,000 & 21,140 & 1.27 \\
8 & 2.5 & 2 & 45.2 & 9000 & 32,200 & 1.39 \\
9 & 1 & 2 & 45.9 & 9200 & 43,300 & 1.43 \\
\hline
\end{tabular}

Polymerization conditions: $\mathrm{R}=[\mathrm{MMA}]_{0}:[\mathrm{EBPA}]_{0}:\left[\mathrm{Fe}(\mathrm{acac})_{3}\right]_{0}:\left[\mathrm{PPh}_{3}\right]_{0}:[\mathrm{ACHN}]_{0}=200: 1: x: 0.3: 1(x=0.03$ (150 ppm), $0.02(100 \mathrm{ppm}), 0.015(75 \mathrm{ppm}), 0.001(5 \mathrm{ppm}), 0.0005$ (2.5 ppm), and 0.0002 (1.0 ppm)), $V_{\text {MMA }}=1.0 \mathrm{~mL}, V_{\text {toluene }}=1.0 \mathrm{~mL}, \mathrm{~T}=90^{\circ} \mathrm{C} ;{ }^{\mathrm{a}} M_{\mathrm{n}, \text { th }}=\left([\mathrm{M}]_{0} /[\mathrm{I}]_{0}\right) \times M_{\mathrm{n}, \mathrm{MMA}} \times$ conv. $\%$.

\subsection{Effect of Concentration of ACHN on Polymerization of $M M A$}

In order to examine the effect of the concentration of $\mathrm{ACHN}$ on the polymerization, we kept the molar ratio of $[\mathrm{MMA}]_{0}:[\mathrm{EBPA}]_{0}:\left[\mathrm{Fe}(\mathrm{acac})_{3}\right]_{0}:\left[\mathrm{PPh}_{3}\right]_{0}$ constant and changed the amount of ACHN constantly to carry out the polymerization of MMA. As shown in Table 4, when $[\mathrm{ACHN}]_{0} /[\mathrm{EBPA}]_{0}=0.1$ (Entry 1 in Table 4 ), no polymers were obtained after $2.5 \mathrm{~h}$. However, as the concentration of $\mathrm{ACHN}$ increased, the monomer conversion increased under the same polymerization time $(2.5 \mathrm{~h})$ as expected by the mechanism of ICAR ATRP $[60-65,69]$. When $[\mathrm{ACHN}]_{0} /[\mathrm{EBPA}]_{0}=2.5$ (Entry 6 in Table 4), the monomer conversion could achieve $73.5 \%$ after $2.5 \mathrm{~h}$ with a controlled molecular weight distribution $\left(M_{\mathrm{w}} / M_{\mathrm{n}}=1.21\right)$.

Table 4. Effect of the concentration of $1,1^{\prime}$-azobis (cyclohexanecarbonitrile) (ACHN) on ICAR ATRP of MMA.

\begin{tabular}{cccccc}
\hline Entry & $\boldsymbol{x}$ & Conv. $(\%)$ & $\boldsymbol{M}_{\mathbf{n}, \mathbf{t h}}{ }^{\mathbf{a}} \mathbf{( g / m o l )}$ & $\boldsymbol{M}_{\mathbf{n}, \mathbf{G P C}}(\mathbf{g} / \mathbf{m o l})$ & $\boldsymbol{M}_{\mathbf{w}} / \boldsymbol{M}_{\mathbf{n}}$ \\
\hline 1 & 0.1 & - & - & - & - \\
2 & 0.5 & 24.4 & 4900 & 10,400 & 1.19 \\
3 & 1.0 & 48.0 & 9600 & 16,400 & 1.30 \\
4 & 1.5 & 62.6 & 12,500 & 16,700 & 1.17 \\
5 & 2.0 & 63.2 & 12,600 & 18,400 & 1.17 \\
6 & 2.5 & 73.5 & 14,700 & 19,900 & 1.21 \\
\hline
\end{tabular}

Polymerization conditions: $\mathrm{R}=[\mathrm{MMA}]_{0}:[\mathrm{EBPA}]_{0}:\left[\mathrm{Fe}(\mathrm{acac})_{3}\right]_{0}:\left[\mathrm{PPh}_{3}\right]_{0}:[\mathrm{ACHN}]_{0}=200: 1: 0.02: 0.3: x(x=0.1$, $0.5,1.0,1.5,2.0$ and 2.5$), V_{\mathrm{MMA}}=1.0 \mathrm{~mL}, V_{\text {toluene }}=1.0 \mathrm{~mL}, \mathrm{~T}=90^{\circ} \mathrm{C}$, polymerization time $=2.5 \mathrm{~h}$; ${ }^{\mathrm{a}} M_{\mathrm{n}, \mathrm{th}}=\left([\mathrm{M}]_{0} /[\mathrm{I}]_{0}\right) \times M_{\mathrm{n}, \mathrm{MMA}} \times$ conv. $\%$.

\subsection{Variation of the Target Degree of Polymerization}

In order to examine the effect of polymerization degree, the polymerizations of MMA were conducted with various molar ratios of monomer. We keep the amount of solvent, catalyst, and initiator constant, and change the amount of monomer to carry out the polymerization. When DP $=300$, the monomer conversion is $43.9 \%$ after $2.5 \mathrm{~h}\left(M_{\mathrm{w}} / M_{\mathrm{n}}=1.15\right)$ (Entry 1 in Table 5). When DP $=1000$, the monomer conversion decreased to $36.3 \%$ (Entry 1 in Table 5). This phenomenon showed that the polymerization rate became slower as the absolute concentrations of the thermal initiator is decreased and the molecular weight distributions changed to a little broader as the amount of monomer increased, but the molecular weight distribution $\left(M_{\mathrm{w}} / M_{\mathrm{n}}=1.24\right)$ was still acceptable and $M_{\mathrm{n}, \mathrm{GPC}}$ 
$\left(M_{\mathrm{n}, \mathrm{GPC}}=43,300 \mathrm{~g} / \mathrm{mol}\right)$ was closer to $M_{\mathrm{n}, \mathrm{th}}\left(M_{\mathrm{n}, \mathrm{th}}=36,300 \mathrm{~g} / \mathrm{mol}\right)$. Therefore, the activity of this polymerization system was much high even under a high target polymerization degree.

Table 5. Effect of molar ratios of monomer on ICAR ATRP of MMA

\begin{tabular}{|c|c|c|c|c|c|}
\hline Entry & $\mathbf{R}$ & Conv. $(\%)$ & ${ }^{\text {a }} M_{n, t h}(g / m o l)$ & $M_{\mathrm{n}, \mathrm{GPC}}(\mathrm{g} / \mathrm{mol})$ & $M_{\mathrm{w}} / M_{\mathrm{n}}$ \\
\hline 1 & 300:1:0.02:0.3:1 & 43.9 & 13,200 & 21,500 & 1.15 \\
\hline 2 & 400:1:0.02:0.3:1 & 43.0 & 17,200 & 24,900 & 1.16 \\
\hline 3 & 800:1:0.02:0.3:1 & 39.6 & 31,700 & 41,100 & 1.20 \\
\hline 4 & $1000: 1: 0.02: 0.3: 1$ & 36.3 & 36,300 & 43,300 & 1.24 \\
\hline
\end{tabular}

\subsection{Polymerization Mechanism and Polymerization Kinetics}

The possible polymerization mechanism of iron(III)-mediated ICAR ATRP is shown in Scheme 1. We assume that, in the beginning, radicals produced by the azo initiator ( $\mathrm{ACHN}$ ) reduce $\mathrm{Fe}(\mathrm{acac})_{3}$ to $\mathrm{Fe}(\mathrm{acac})_{2}$, even though the mechanism behind this reduction is not yet fully understood. Then, the generated active $\mathrm{Fe}(\mathrm{II})$ species can seize the halogen from the ATRP initiator (R-X) and form the $\mathrm{X}-\mathrm{Fe}(\mathrm{acac})_{2} / \mathrm{L}$ as well as the propagating radical. The next steps are the same as our previous document [69]. The difference between ICAR ATRP and normal ATRP is that the azo-initiator (ACHN here) can produce free radicals constantly to activate the $\mathrm{Fe}(\mathrm{III})$ species to establish a dynamic equilibrium between the active Fe(II) species and Fe(III) species and therefore to mediate the concentration of propagating radicals to control the polymerization.

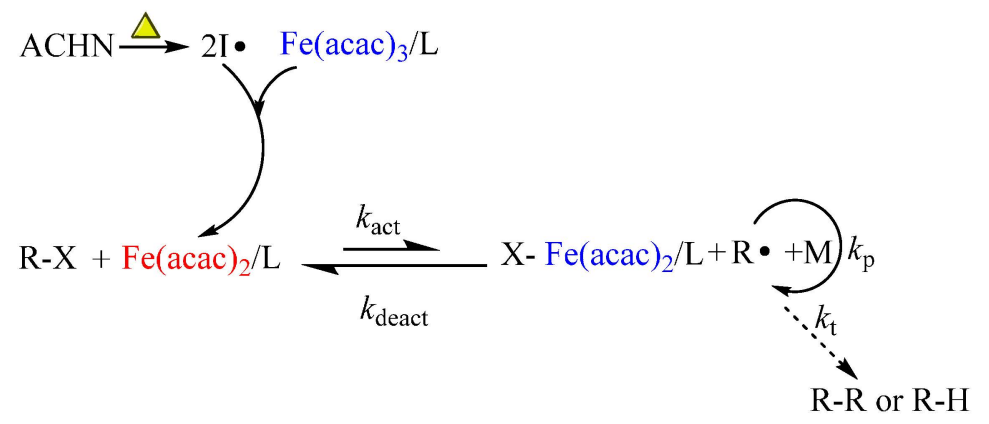

Scheme 1. Possible polymerization mechanism of ICAR ATRP with $\mathrm{Fe}(\mathrm{acac})_{3}$ as the initial catalyst and ACHN as the azo-initiator.

In order to further investigate the detailed polymerization behaviors, the polymerization kinetics of MMA were conducted with the molar ratio of $[\mathrm{MMA}]_{0}:[\mathrm{EBPA}]_{0}:\left[\mathrm{PPh}_{3}\right]_{0}:[\mathrm{ACHN}]_{0}=200: 1: 0.3: 1$ under various concentration of iron catalyst firstly. Figure $1 \mathrm{~A}$ shows the kinetic plots of $\ln \left([\mathrm{M}]_{0} /[\mathrm{M}]\right)$ versus time. We can see that the polymerization was approximately first order with respect to the monomer concentration, indicating that the propagating radicals remained almost constant during the polymerization in the three cases. From Figure 1B, it can be seen that the molecular weights increased linearly with monomer conversion while keeping narrow molecular weight distributions $\left(M_{\mathrm{w}} / M_{\mathrm{n}} \leqslant 1.3\right)$. Furthermore, we also studied the polymerization kinetics under different concentration of azo-initiator ACHN. As is shown in Figure 2A, the polymerization was basically first order with respect to the monomer concentration. Moreover, the increase of the amount of ACHN can shorten the induction period of the polymerization system and accelerate the polymerization rate at the same time. Similarly, from Figure 2B, the linear increase of the molecular weights with monomer conversion and narrow molecular weight distributions can also observed. These polymerization kinetics further demonstrated the "living" features of this iron-mediated homogeneous ICAR ATRP system using $\mathrm{Fe}(\mathrm{acac})_{3}$ as the catalyst and $\mathrm{ACHN}$ as the azo-initiator. 


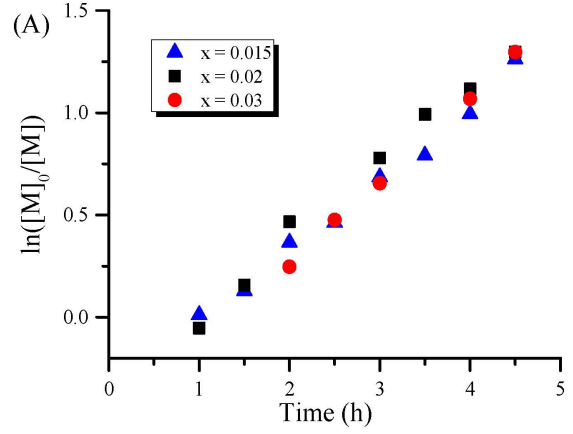

A

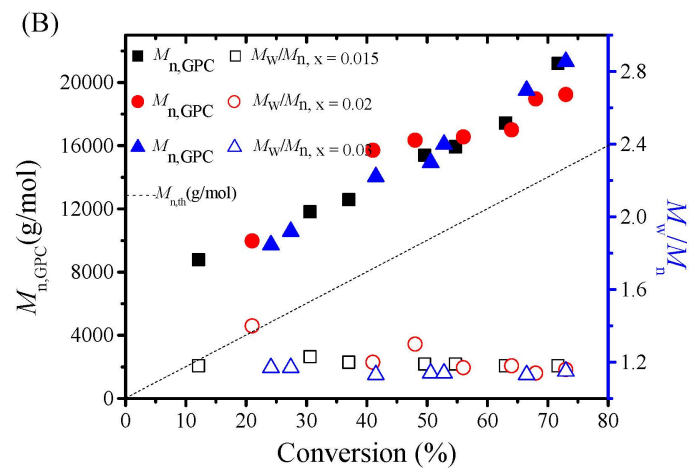

B

Figure 1. $\ln \left([\mathrm{M}]_{0} /[\mathrm{M}]\right)$ as a function of time (A) and evolution of number-average molecular weight $\left(M_{n, G P C}\right)$ and molecular weight distribution $\left(M_{w} / M_{n}\right)$ versus conversion (B) for ICAR ATRP of MMA with various iron catalyst concentration. Polymerization conditions: $[\mathrm{MMA}]_{0}:[\mathrm{EBPA}]_{0}:\left[\mathrm{Fe}(\mathrm{acac})_{3}\right]_{0}:\left[\mathrm{PPh}_{3}\right]_{0}:[\mathrm{ACHN}]_{0}=200: 1: x: 0.3: 1(x=0.015,0.02,0.03), V_{\mathrm{MMA}}=1.0 \mathrm{~mL}$, $V_{\text {toluene }}=1.0 \mathrm{~mL}, \mathrm{~T}=90^{\circ} \mathrm{C}$.

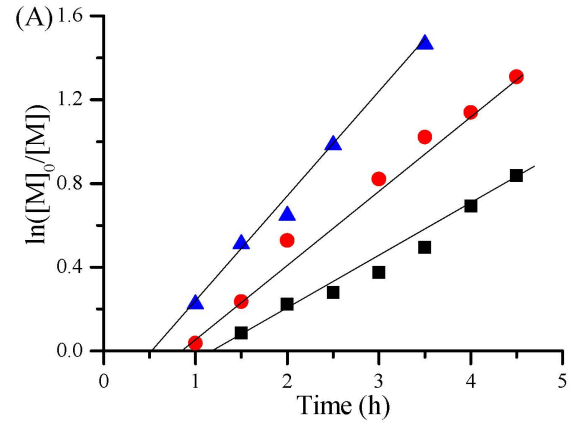

A

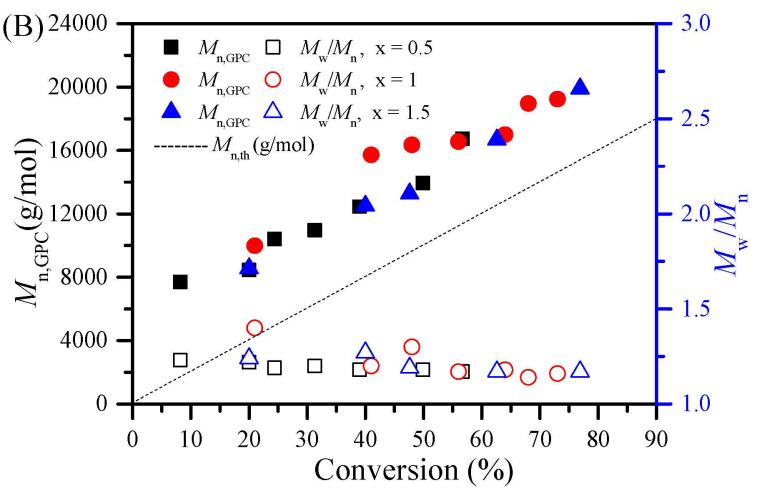

B

Figure 2. $\ln \left([\mathrm{M}]_{0} /[\mathrm{M}]\right)$ as a function of time (A) and evolution of number-average molecular weight $\left(M_{n, G P C}\right)$ and molecular weight distribution $\left(M_{\mathrm{w}} / M_{\mathrm{n}}\right)$ versus conversion (B) for ICAR ATRP of MMA with various ACHN concentration. Polymerization conditions: $[\mathrm{MMA}]_{0}:[\mathrm{EBPA}]_{0}:\left[\mathrm{Fe}(\mathrm{acac})_{3}\right]_{0}:\left[\mathrm{PPh}_{3}\right]_{0}:[\mathrm{ACHN}]_{0}=200: 1: 0.02: 0.3: x(x=0.5,1,1.5), V_{\mathrm{MMA}}=1.0 \mathrm{~mL}$, $V_{\text {toluene }}=1.0 \mathrm{~mL}, \mathrm{~T}=90^{\circ} \mathrm{C}$.

\subsection{Analysis of Chain-End and Chain Extension}

The chain-end of the resultant PMMA was analyzed by ${ }^{1} \mathrm{H}$ NMR spectroscopy. The signals at $\delta=4.0 \mathrm{ppm}(\boldsymbol{c}$ in Figure 3$)$ and $7.3 \mathrm{ppm}(\boldsymbol{b}$ in Figure 3$)$ were assigned to the methylene and phenyl groups in the initiator EBPA, respectively, which indicated the initiator EBPA moieties were attached to the polymer chain-end successfully. The signal at $\delta=3.60 \mathrm{ppm}$ ( $\boldsymbol{a}$ in Figure 3) corresponded to methyl ester groups in PMMA. The signal at $\delta=3.78 \mathrm{ppm}\left(\boldsymbol{a}^{\prime}\right.$ in Figure 3$)$ was assigned to methyl ester group at the chain-end $[98,99]$. Further, we conducted the chain-extension experiment using the resultant PMMA as the macroinitiator $\left(M_{\mathrm{n}, \mathrm{GPC}}=12,700 \mathrm{~g} / \mathrm{mol}, M_{\mathrm{w}} / M_{\mathrm{n}}=1.21\right), \mathrm{Fe}(\mathrm{acac})_{3}$ as the catalyst and ACHN as the azo-initiator with fresh MMA. As is shown in Figure 4, the $M_{n, G P C}$ increased to $29,000 \mathrm{~g} / \mathrm{mol}\left(M_{\mathrm{W}} / M_{\mathrm{n}}=1.31\right)$ after chain extension. Based on the above phenomenon, we can draw the conclusion that polymeric product has a high degree of chain-end functionality, further verifying the "living" features of this polymerization system. However, the GPC trace of PMMA after chain-extension showed a little shoulder, which indicated that the high degree of chain-end 
functionality was somewhat limited. This may be caused by the use of a relatively large amount of thermal initiator ACHN relative to alkyl halide.

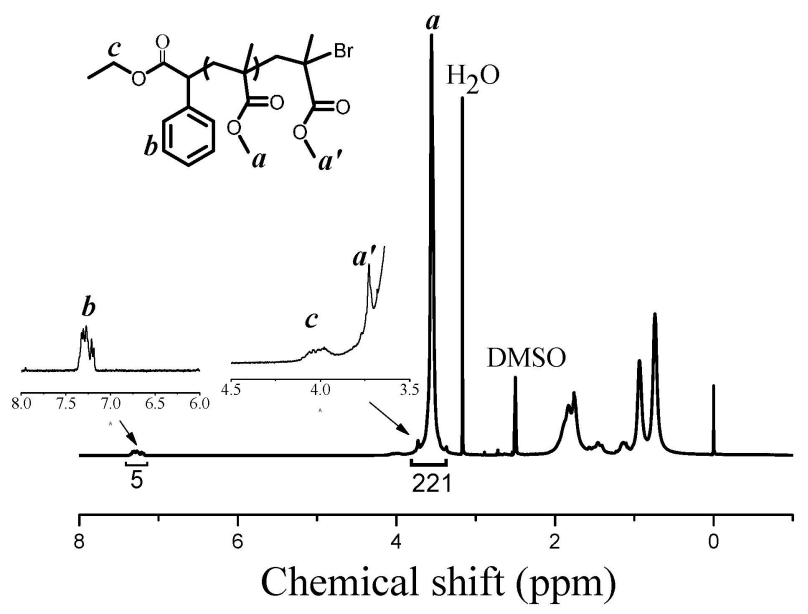

Figure 3. ${ }^{1} \mathrm{H}$ NMR spectrum of the resultant PMMA with DMSO- $\mathrm{d}_{6}$ as solvent and tetramethylsilane (TMS) as internal standard. Polymerization conditions of sample PMMA $\left(M_{\mathrm{n}, \mathrm{GPC}}=6570 \mathrm{~g} / \mathrm{mol}\right.$, $\left.M_{\mathrm{W}} / M_{\mathrm{n}}=1.16\right):[\mathrm{MMA}]_{0}:[\mathrm{EBPA}]_{0}:\left[\mathrm{Fe}(\mathrm{acac})_{3}\right]_{0}:\left[\mathrm{PPh}_{3}\right]_{0}:[\mathrm{ACHN}]_{0}=200: 2: 0.03: 0.3: 1, V_{\mathrm{MMA}}=2.0 \mathrm{~mL}$, $V_{\text {toluene }}=1.0 \mathrm{~mL}, \mathrm{~T}=90^{\circ} \mathrm{C}$, polymerization time $=1.5 \mathrm{~h}$.

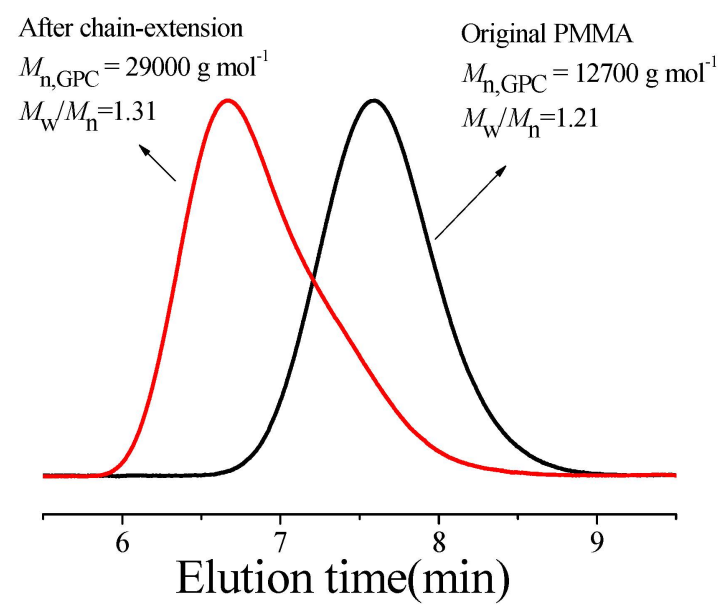

Figure 4. Gel permeation chromatograph (GPC) traces of PMMA before and after chain extension. Chain extension polymerization conditions: $[\mathrm{MMA}]_{0}:[\mathrm{PMMA}]_{0}:\left[\mathrm{Fe}(\mathrm{acac})_{3}\right]_{0}:\left[\mathrm{PPh}_{3}\right]_{0}:[\mathrm{ACHN}]_{0}=$ 200:1:1:3:0.75, $V_{\mathrm{MMA}}=0.2 \mathrm{~mL}, V_{\text {toluene }}=1.0 \mathrm{~mL}, \mathrm{~T}=90^{\circ} \mathrm{C}$, polymerization time $=18 \mathrm{~h}$.

\section{Conclusions}

A facile iron-mediated homogeneous ICAR ATRP system was developed using organometallic catalyst $\mathrm{Fe}(\mathrm{acac})_{3}$ and azo-initiator $\mathrm{ACHN}$ successfully in toluene. The polymerization of MMA can be carried out smoothly even if the amount of the iron catalyst decreases as low as to 1 ppm, fully demonstrating high activity of the iron catalytic system.

Acknowledgments: The financial support from the National Natural Science Foundation of China (No. 21174096, 21274100), the Specialized Research Fund for the Doctoral Program of Higher Education (No. 20123201130001), the Project of Science and Technology Development Planning of Suzhou (No. ZXG201413, SYG201430), the Project of Science and Technology Development Planning of Jiangsu Province (No. BK20141192) and the Project Funded by the Priority Academic Program Development of Jiangsu Higher Education Institutions (PAPD) is gratefully acknowledged. 
Author Contributions: Jian Wu, Xiaowu Jiang, Lifen Zhang, Zhenping Cheng designed the experiments. Jian Wu and Xiaowu Jiang performed the experiments and analyzed the data. Lifen Zhang and Zhenping Cheng wrote the manuscript. Xiulin Zhu contributed to the discussion.

Conflicts of Interest: The authors declare no conflict of interest.

\section{References}

1. Shipp, D.A. Reversible-deactivation radical polymerizations. Polym. Rev. 2011, 51, 99-103. [CrossRef]

2. Zhao, J.F.; Wang, W.X.; Bai, L.J.; Zhou, L.L.; Cheng, Z.P.; Zhang, Z.B.; Zhu, X.L. Reversible-deactivation radical polymerization mediated by $\mathrm{CuSO}_{4} \cdot 5 \mathrm{H}_{2} \mathrm{O}$ : An alternative and promising copper(II)-based catalyst. Polym. Chem. 2012, 3, 3220-3223. [CrossRef]

3. Wang, Y.; Zhong, M.; Zhu, W.; Peng, C.H.; Zhang, Y.; Konkolewicz, D.; Bortoamei, N.; Isse, A.A.; Gennaro, A.; Matyjaszewski, K. Reversible-deactivation radical polymerization in the presence of metallic copper. Comproportionation-disproportionation equilibria and kinetics. Macromolecules 2013, 46, 3793-3802. [CrossRef]

4. Peng, C.H.; Yang, T.Y.; Zhao, Y.G.; Fu, X.F. Reversible deactivation radical polymerization mediated by cobalt complexes: Recent progress and perspectives. Org. Biomol. Chem. 2014, 12, 8580-8587. [CrossRef] [PubMed]

5. Poli, R.; Allan, L.E.; Shaver, M.P. Iron-mediated reversible deactivation controlled radical polymerization. Prog. Polym. Sci. 2014, 39, 1827-1845. [CrossRef]

6. Feng, C.; Lu, G.L.; Sun, G.; Liu, X.W.; Huang, X.Y. t BCPMA: A new trifunctional acrylic monomer for convenient synthesis of a well-defined amphiphilic graft copolymer by successive RDRP. Polym. Chem. 2014, 5, 6027-6038. [CrossRef]

7. Zhang, M.M.; Cunningham, M.F.; Hutchinson, R.A. Aqueous copper(0) mediated reversible deactivation radical polymerization of 2-hydroxyethyl acrylate. Polym. Chem. 2015, 6, 6509-6518. [CrossRef]

8. Otsu, T.; Yoshida, M.; Tazaki, T. A model for living radical polymerization. Makromol. Chem. Rapid Commun. 1982, 3, 133-140. [CrossRef]

9. Otsu, T.; Yoshida, M. Role of initiator-transfer agent-terminator (iniferter) in radical polymerizations: Polymer design by organic disulfides as iniferters. Makromol. Chem. Rapid Commun. 1982, 3, 127-132. [CrossRef]

10. Otsu, T. Iniferter concept and living radical polymerization. J. Polym. Sci. Part A 2000, 38, 2121-2136. [CrossRef]

11. Šebenik, A. Living free-radical block copolymerization using thio-iniferters. Prog. Polym. Sci. 1998, 23, 875-917. [CrossRef]

12. García-Valdez, O.; Champagne-Hartley, R.; Saldívar-Guerra, E.; Champagne, P.; Cunningham, M.F. Modification of chitosan with polystyrene and poly(n-butyl acrylate) via nitroxide-mediated polymerization and grafting from approach in homogeneous media. Polym. Chem. 2015, 6, 2827-2836. [CrossRef]

13. Chen, S.; Alves, M.H.; Save, M.; Billon, L. Synthesis of amphiphilic diblock copolymers derived from renewable dextran by nitroxide mediated polymerization: Towards hierarchically structured honeycomb porous films. Polym. Chem. 2014, 5, 5310-5319. [CrossRef]

14. Cherifi, N.; Issoulie, A.; Khoukh, A.; Benaboura, A.; Save, M.; Derail, C.; Billon, L. Synthetic methodology effect on the microstructure and thermal properties of poly( $n$-butyl acrylate-co-methyl methacrylate) synthesized by nitroxide mediated polymerization. Polym. Chem. 2011, 2, 1769-1777. [CrossRef]

15. Nicolas, J.; Guillaneuf, Y.; Lefay, C.; Bertin, D.; Gigmes, D.; Charleux, B. Nitroxide-mediated polymerization. Prog. Polym. Sci. 2013, 38, 63-235. [CrossRef]

16. Bertin, D.; Gigmes, D.; Marque, S.R.; Tordo, P. Kinetic subtleties of nitroxide mediated polymerization. Chem. Soc. Rev. 2011, 40, 2189-2198. [CrossRef] [PubMed]

17. Grubbs, R.B. Nitroxide-mediated radical polymerization: Limitations and versatility. Polym. Rev. 2011, 51, 104-137. [CrossRef]

18. Sciannamea, V.; Jérôme, R.; Detrembleur, C. In-situ nitroxide-mediated radical polymerization (NMP) processes: Their understanding and optimization. Chem. Rev. 2008, 108, 1104-1126. [CrossRef] [PubMed]

19. Kato, M.; Kamigaito, M.; Sawamoto, M.; Higashimura, T. Polymerization of methyl methacrylate with the carbon tetrachloride/dichlorotris-(triphenylphosphine) ruthenium (II)/methylaluminum bis (2,6-di-tert-butylphenoxide) initiating system: Possibility of living radical polymerization. Macromolecules 1995, 28, 1721-1723. [CrossRef] 
20. Wang, J.S.; Matyjaszewski, K. Controlled/"living" radical polymerization. Atom transfer radical polymerization in the presence of transition-metal complexes. J. Am. Chem. Soc. 1995, 117, 5614-5615. [CrossRef]

21. Matyjaszewski, K.; Xia, J. Atom transfer radical polymerization. Chem. Rev. 2001, 101, 2921-2990. [CrossRef] [PubMed]

22. Kamigaito, M.; Ando, T.; Sawamoto, M. Metal-catalyzed living radical polymerization. Chem. Rev. 2001, 101, 3689-3746. [CrossRef] [PubMed]

23. Ouchi, M.; Terashima, T.; Sawamoto, M. Transition metal-catalyzed living radical polymerization: Toward perfection in catalysis and precision polymer synthesis. Chem. Rev. 2009, 109, 4963-5050. [CrossRef] [PubMed]

24. Tsarevsky, N.V.; Matyjaszewski, K. “Green” atom transfer radical polymerization: from process design to preparation of well-defined environmentally friendly polymeric materials. Chem. Rev. 2007, 107, 2270-2299. [CrossRef] [PubMed]

25. Bai, L.J.; Zhang, L.F.; Cheng, Z.P.; Zhu, X.L. Activators generated by electron transfer for atom transfer radical polymerization: recent advances in catalyst and polymer chemistry. Polym. Chem. 2012, 3, 2685-2697. [CrossRef]

26. He, W.W.; Jiang, H.J.; Zhang, L.F.; Cheng, Z.P.; Zhu, X.L. Atom transfer radical polymerization of hydrophilic monomers and its applications. Polym. Chem. 2013, 4, 2919-2938. [CrossRef]

27. Pan, J.L.; Li, Z.; Zhang, L.F.; Cheng, Z.P.; Zhu, X.L. Iron-mediated AGET ATRP of styrene and methyl methacrylate using ascorbic acid sodium salt as reducing agent. Chin. J. Polym. Sci. 2014, 32, 1010-1018. [CrossRef]

28. Jiang, X.W.; Luo, Y.J.; Li, Z.; Zhang, L.F.; Cheng, Z.P.; Zhu, X.L. Thermoregulated phase transfer catalysis in aqueous/organic biphasic system: facile and highly efficient ATRP catalyst separation and recycling in situ using typical alkyl halide as initiator. Polym. Chem. 2015, 6, 6394-6401. [CrossRef]

29. Yu, J.; Liu, Y.P.; Liu, X.H.; Wang, C.P.; Wang, J.F.; Chu, F.X.; Tang, C.B. Integration of renewable cellulose and rosin towards sustainable copolymers by "grafting from" ATRP. Green Chem. 2014, 16, 1854-1864. [CrossRef]

30. Ouchi, M.; Tokuoka, S.; Sawamoto, M. Halogen donors in metal-catalyzed living radical polymerization: Control of the equilibrium between dormant and active species. Macromolecules 2008, 41, 518-520. [CrossRef]

31. Pan, J.L.; Zhang, L.F.; Bai, L.J.; Zhang, Z.B.; Chen, H.; Cheng, Z.P.; Zhu, X.L. Atom transfer radical polymerization of methyl methacrylate with a thermo-responsive ligand: Construction of thermoregulated phase-transfer catalysis in an aqueous-organic biphasic system. Polym. Chem. 2013, 4, 2876-2883. [CrossRef]

32. Zhu, G.H.; Zhang, L.F.; Pan, X.Q.; Zhang, W.; Cheng, Z.P.; Zhu, X.L. Facile soap-free miniemulsion polymerization of methyl methacrylate via reverse atom transfer radical polymerization. Macromol. Rapid Commun. 2012, 33, 2121-2126. [CrossRef] [PubMed]

33. Ding, M.Q.; Jiang, X.W.; Zhang, L.F.; Cheng, Z.P.; Zhu, X.L. Recent progress on transition metal catalyst separation and recycling in ATRP. Macromol. Rapid Commun. 2015, 36, 1702-1721. [CrossRef] [PubMed]

34. Bai, L.J.; Zhang, L.F.; Pan, J.L.; Zhu, J.; Cheng, Z.P.; Zhu, X.L. Developing a synthetic approach with thermoregulated phase-transfer catalysis: facile access to metal-mediated living radical polymerization of methyl methacrylate in aqueous/organic biphasic system. Macromolecules 2013, 46, 2060-2066. [CrossRef]

35. Cheng, Z.P.; Zhu, X.L.; Zhang, L.F.; Zhou, N.C.; Chen, J.Y. Homogeneous solution reverse atom transfer radical polymerization of methyl methacrylate. J. Macromol. Sci. Pure Appl. Chem. 2003, 40, 371-385. [CrossRef]

36. Miao, J.; He, W.W.; Zhang, L.F.; Wang, Y.; Cheng, Z.P.; Zhu, X.L. AGET ATRP of water-soluble PEGMA: Fast living radical polymerization mediated by iron catalyst. J. Polym. Sci. Part A 2012, 50, 2194-2200. [CrossRef]

37. Cheng, Z.P.; Zhu, X.L.; Zhang, L.F.; Zhou, N.C.; Xue, X.R. RATRP of MMA in AIBN $/ \mathrm{FeCl}_{3} / \mathrm{PPh}_{3}$ initiation system under microwave irradiation. Polym. Bull. 2003, 49, 363-369. [CrossRef]

38. Jiang, X.W.; Liu, Y.; Ding, M.Q.; Zhang, L.F.; Cheng, Z.P.; Zhu, X.L. AGET ATRP of methyl methacrylate based on thermoregulated phase transfer catalysis in organic/aqueous biphasic system: Facile and highly efficient in situ catalyst/ligand separation and recycling. Macromol. Chem. Phys. 2015, 216, 1171-1179. [CrossRef]

39. Ding, M.Q.; Jiang, X.W.; Peng, J.Y.; Zhang, L.F.; Cheng, Z.P.; Zhu, X.L. Diffusion-regulated phase-transfer catalysis for atom transfer radical polymerization of methyl methacrylate in an aqueous/organic biphasic system. Macromol. Rapid Commun. 2015, 36, 538-546. [CrossRef] [PubMed] 
40. Pan, J.L.; Zhang, B.J.; Jiang, X.W.; Zhang, L.F.; Cheng, Z.P.; Zhu, X.L. Cu(II)-mediated atom transfer radical polymerization of methyl methacrylate via a strategy of thermo-regulated phase-separable catalysis in a liquid/liquid biphasic system: Homogeneous catalysis, facile heterogeneous separation, and recycling. Macromol. Rapid Commun. 2014, 35, 1615-1621. [CrossRef] [PubMed]

41. Du, X.Y.; Pan, J.L.; Chen, M.T.; Zhang, L.F.; Cheng, Z.P.; Zhu, X.L. Thermo-regulated phase separable catalysis (TPSC)-based atom transfer radical polymerization in a thermo-regulated ionic liquid. Chem. Commun. 2014, 50, 9266-9269. [CrossRef] [PubMed]

42. Miao, J.; Jiang, H.J.; Zhang, L.F.; Wu, Z.Q.; Cheng, Z.P.; Zhu, X.L. AGET ATRP of methyl methacrylate via a bimetallic catalyst. RSC Adv. 2012, 2, 840-847. [CrossRef]

43. Fujimura, K.; Ouchi, M.; Sawamoto, M. Ferrocene cocatalysis for iron-catalyzed living radical polymerization: Active, robust, and sustainable system under concerted catalysis by two iron complexes. Macromolecules 2015, 48, 4294-4300. [CrossRef]

44. Chiefari, J.; Chong, Y.K.; Ercole, F.; Krstina, J.; Jeffery, J.; Le, T.P.; Mayadunne, R.T.; Meijs, G.F.; Moad, G.; Rizzardo, E. Living free-radical polymerization by reversible addition-fragmentation chain transfer: The RAFT process. Macromolecules 1998, 31, 5559-5562. [CrossRef]

45. Haven, J.J.; Guerrero-Sanchez, C.; Keddie, D.J.; Moad, G.; Thang, S.H.; Schubert, U.S. One pot synthesis of higher order quasi-block copolymer libraries via sequential RAFT polymerization in an automated synthesizer. Polym. Chem. 2014, 5, 5236-5246. [CrossRef]

46. Li, Z.; Chen, W.; Zhang, Z.B.; Zhang, L.F.; Cheng, Z.P.; Zhu, X.L. A surfactant-free emulsion RAFT polymerization of methyl methacrylate in a continuous tubular reactor. Polym. Chem. 2015, 6, 1937-1943. [CrossRef]

47. Shi, P.; Zhou, H.; Gao, C.; Wang, S.; Sun, P.; Zhang, W. Macro-RAFT agent mediated dispersion copolymerization: A small amount of solvophilic co-monomer leads to a great change. Polym. Chem. 2015, 6, 4911-4920. [CrossRef]

48. Xu, T.C.; Zhang, L.F.; Cheng, Z.P.; Zhu, X.L. A novel methacrylate with a bisphosphonate group: RAFT polymerization and flame retardant property of the resultant polymers. Polym. Chem. 2015, 6, 2283-2289. [CrossRef]

49. Keddie, D.J. A guide to the synthesis of block copolymers using reversible-addition fragmentation chain transfer (RAFT) polymerization. Chem. Soc. Rev. 2014, 43, 496-505. [CrossRef] [PubMed]

50. Moad, G.; Rizzardo, E.; Thang, S.H. RAFT polymerization and some of its applications. Chem. Asian J. 2013, 8, 1634-1644. [CrossRef] [PubMed]

51. Ahmed, M.; Narain, R. Progress of RAFT based polymers in gene delivery. Prog. Polym. Sci. 2013, 38, 767-790. [CrossRef]

52. Gregory, A.; Stenzel, M.H. Complex polymer architectures via RAFT polymerization: From fundamental process to extending the scope using click chemistry and nature's building blocks. Prog. Polym. Sci. 2012, 37, 38-105. [CrossRef]

53. Beija, M.; Marty, J.D.; Destarac, M. RAFT/MADIX polymers for the preparation of polymer/inorganic nanohybrids. Prog. Polym. Sci. 2011, 36, 845-886. [CrossRef]

54. Smith, A.E.; Xu, X.; McCormick, C.L. Stimuli-responsive amphiphilic (co)polymers via RAFT polymerization. Prog. Polym. Sci. 2010, 35, 45-93. [CrossRef]

55. Boyer, C.; Bulmus, V.; Davis, T.P.; Ladmiral, V.; Liu, J.; Perrier, S. Bioapplications of RAFT polymerization. Chem. Rev. 2009, 109, 5402-5436. [CrossRef] [PubMed]

56. Matyjaszewski, K.; Gaynor, S.G.; Müller, A.H. Preparation of hyperbranched polyacrylates by atom transfer radical polymerization. 2. Kinetics and mechanism of chain growth for the self-condensing vinyl polymerization of 2-((2-bromopropionyl) oxy) ethyl acrylate. Macromolecules 1997, 30, 7034-7041. [CrossRef]

57. Sheiko, S.S.; Sumerlin, B.S.; Matyjaszewski, K. Cylindrical molecular brushes: Synthesis, characterization, and properties. Prog. Polym. Sci. 2008, 33, 759-785. [CrossRef]

58. Gao, H.; Matyjaszewski, K. Synthesis of functional polymers with controlled architecture by CRP of monomers in the presence of cross-linkers: From stars to gels. Prog. Polym. Sci. 2009, 34, 317-350. [CrossRef]

59. Konkolewicz, D.; Monteiro, M.J.; Perrier, S. Dendritic and hyperbranched polymers from macromolecular units: elegant approaches to the synthesis of functional polymers. Macromolecules 2011, 44, 7067-7087. [CrossRef] 
60. Mueller, L.; Jakubowski, W.; Tang, W.; Matyjaszewski, K. Successful chain extension of polyacrylate and polystyrene macroinitiators with methacrylates in an ARGET and ICAR ATRP. Macromolecules 2007, 40, 6464-6472. [CrossRef]

61. Konkolewicz, D.; Magenau, A.J.; Averick, S.E.; Simakova, A.; He, H.; Matyjaszewski, K. ICAR ATRP with ppm Cu catalyst in water. Macromolecules 2012, 45, 4461-4468. [CrossRef]

62. Guo, T.; Zhang, L.F.; Pan, X.Q.; Li, X.H.; Cheng, Z.P.; Zhu, X.L. A highly active homogeneous ICAR ATRP of methyl methacrylate using ppm levels of organocopper catalyst. Polym. Chem. 2013, 4, 3725-3734. [CrossRef]

63. Zhang, B.J.; Jiang, X.W.; Zhang, L.F.; Cheng, Z.P.; Zhu, X.L. Fe (iii)-mediated ICAR ATRP in ap-xylene/PEG-200 biphasic system: Facile and highly efficient separation and recycling of an iron catalyst. Polym. Chem. 2015, 6, 6616-6622. [CrossRef]

64. Okada, S.; Park, S.; Matyjaszewski, K. Initiators for continuous activator regeneration atom transfer radical polymerization of methyl methacrylate and styrene with $N$-heterocyclic carbene as ligands for Fe-based catalysts. ACS Macro Lett. 2014, 3, 944-947. [CrossRef]

65. Zhang, L.F.; Miao, J.; Cheng, Z.P.; Zhu, X.L. Iron-mediated ICAR ATRP of styrene and methyl methacrylate in the absence of thermal radical initiator. Macromol. Rapid Commun. 2010, 31, 275-280. [CrossRef] [PubMed]

66. Pintauer, T.; Matyjaszewski, K. Atom transfer radical addition and polymerization reactions catalyzed by ppm amounts of copper complexes. Chem. Soc. Rev. 2008, 37, 1087-1097. [CrossRef] [PubMed]

67. Jiang, X.W.; Wu, J.; Zhang, L.F.; Cheng, Z.P.; Zhu, X.L. Highly active ppm level organic copper catalyzed photo-induced ICAR ATRP of methyl methacrylate. Macromol. Rapid Commun. 2014, 35, 1879-1885. [CrossRef] [PubMed]

68. Plichta, A.; Li, W.; Matyjaszewski, K. ICAR ATRP of styrene and methyl methacrylate with $\mathrm{Ru}\left(\mathrm{Cp}^{*}\right) \mathrm{Cl}\left(\mathrm{PPh}_{3}\right)_{2}$. Macromolecules 2009, 42, 2330-2332. [CrossRef]

69. Zhu, G.H.; Zhang, L.F.; Zhang, Z.B.; Zhu, J.; Tu, Y.F.; Cheng, Z.P.; Zhu, X.L. Iron-mediated ICAR ATRP of methyl methacrylate. Macromolecules 2011, 44, 3233-3239. [CrossRef]

70. Wang, G.X.; Lu, M.; Liu, Y. ICAR ATRP of methyl methacrylate catalyzed by $\mathrm{FeCl}_{3} \cdot 6 \mathrm{H}_{2} \mathrm{O} /$ succinic acid. J. Appl. Polym. Sci. 2012, 126, 381-386. [CrossRef]

71. Ando, T.; Kamigaito, M.; Sawamoto, M. Iron(II) chloride complex for living radical polymerization of methyl methacrylate 1. Macromolecules 1997, 30, 4507-4510. [CrossRef]

72. Matyjaszewski, K.; Wei, M.; Xia, J.; Gaynor, S.G. Atom transfer radical polymerization of styrene catalyzed by copper carboxylate complexes. Macromol. Chem. Phys. 1998, 199, 2289-2292. [CrossRef]

73. Schroeder, H.; Lake, B.R.; Demeshko, S.; Shaver, M.P.; Buback, M. A Synthetic and multispectroscopic speciation analysis of controlled radical polymerization mediated by amine-bis (phenolate)iron complexes. Macromolecules 2015, 48, 4329-4338. [CrossRef]

74. Nakanishi, S.I.; Kawamura, M.; Kai, H.; Jin, R.H.; Sunada, Y.; Nagashima, H. Well-defined iron complexes as efficient catalysts for "green" atom-transfer radical polymerization of styrene, methyl methacrylate, and butyl acrylate with low catalyst loadings and catalyst recycling. Chem. Eur. J. 2014, 20, 5802-5814. [CrossRef] [PubMed]

75. Simakova, A.; Mackenzie, M.; Averick, S.E.; Park, S.; Matyjaszewski, K. Bioinspired iron-based catalyst for atom transfer radical polymerization. Angew. Chem. Int. Ed. 2013, 52, 12148-12151. [CrossRef] [PubMed]

76. He, W.W.; Zhang, L.F.; Miao, J.; Cheng, Z.P.; Zhu, X.L. Facile iron-mediated AGET ATRP for water-soluble poly(ethylene glycol) monomethyl ether methacrylate in water. Macromol. Rapid Commun. 2012, 33, 1067-1073. [CrossRef] [PubMed]

77. Bai, L.J.; Zhang, L.F.; Zhu, J.; Cheng, Z.P.; Zhu, X.L. Iron(III)-mediated AGET ATRP of styrene using tris(3,6-dioxaheptyl) amine as a ligand. J. Polym. Sci. Part A 2009, 47, 2002-2008. [CrossRef]

78. Zhang, L.F.; Cheng, Z.P.; Lü, Y.T.; Zhu, X.L. A highly active iron-based catalyst system for the AGET ATRP of styrene. Macromol. Rapid Commun. 2009, 30, 543-547. [CrossRef] [PubMed]

79. Luo, R.; Sen, A. Electron-transfer-induced iron-based atom transfer radical polymerization of styrene derivatives and copolymerization of styrene and methyl methacrylate. Macromolecules 2008, 41, 4514-4518. [CrossRef]

80. Mohammad Rabea, A.; Zhu, S. Controlled radical polymerization at high conversion: Bulk ICAR ATRP of methyl methacrylate. Ind. Eng. Chem. Res. 2014, 53, 3472-3477. [CrossRef]

81. Schroeder, H.; Matyjaszewski, K.; Buback, M. Kinetics of Fe-mediated ATRP with triarylphosphines. Macromolecules 2015, 48, 4431-4437. [CrossRef] 
82. Bai, L.J.; Wang, W.X.; Chen, H.; Zhang, L.F.; Cheng, Z.P.; Zhu, X.L. Facile iron(iii)-mediated ATRP of MMA with phosphorus-containing ligands in the absence of any additional initiators. RSC Adv. 2015, 5, 62577-62584. [CrossRef]

83. Xue, Z.G.; He, D.; Xie, X.L. Iron-catalyzed atom transfer radical polymerization. Polym. Chem. 2015, 6, 1660-1687. [CrossRef]

84. Khan, M.Y.; Chen, X.; Lee, S.W.; Noh, S.K. Development of new atom transfer radical polymerization system by iron(III)-metal salts without using any external initiator and reducing agent. Macromol. Rapid Commun. 2013, 34, 1225-1230. [CrossRef] [PubMed]

85. Nishizawa, K.; Ouchi, M.; Sawamoto, M. Phosphine-ligand decoration toward active and robust iron catalysts in LRP. Macromolecules 2013, 46, 3342-3349. [CrossRef]

86. Aoshima, H.; Satoh, K.; Umemura, T.; Kamigaito, M. A simple combination of higher-oxidation-state FeX $\mathrm{X}_{3}$ and phosphine or amine ligand for living radical polymerization of styrene, methacrylate, and acrylate. Polym. Chem. 2013, 4, 3554-3562. [CrossRef]

87. Wang, Y.; Kwak, Y.; Matyjaszewski, K. Enhanced activity of ATRP Fe catalysts with phosphines containing electron donating Groups. Macromolecules 2012, 45, 5911-5915. [CrossRef]

88. Bai, L.J.; Zhang, L.F.; Zhang, Z.B.; Zhu, J.; Zhou, N.C.; Cheng, Z.P.; Zhu, X.L. Alumina additives for fast iron-mediated AGET ATRP of MMA using onium salt as ligand. J. Polym. Sci., Part A 2011, 49, 3970-3979. [CrossRef]

89. Zhang, Y.; Wang, Y.; Matyjaszewski, K. ATRP of methyl acrylate with metallic zinc, magnesium, and iron as reducing agents and supplemental activators. Macromolecules 2011, 44, 683-685. [CrossRef]

90. Deng, Z.J.; Guo, J.N.; Qiu, L.H.; Yuan, C.; Zhou, Y.X.; Yan, F. Iron-mediated AGET ATRP of MMA with sulfosalicylic acid as a ligand. J. Polym. Sci., Part A 2013, 51, 664-671. [CrossRef]

91. Hou, C.; Qu, R.J.; Liu, J.S.; Guo, Z.L.; Wang, C.H.; Ji, C.N.; Sun, C.M.; Wang, C.G. Reverse ATRP of acrylonitrile with diethyl 2,3-dicyano-2,3-diphenyl succinate $/ \mathrm{FeCl}_{3} /$ iminodiacetic acid. Polymer 2006, 47, 1505-1510. [CrossRef]

92. Zhu, S.M.; Yan, D.Y. New ligands for atom-transfer radical polymerization. Macromol. Rapid Commun. 2000, 21, 1209-1213. [CrossRef]

93. Zhu, S.M.; Yan, D.Y. Atom transfer radical polymerization of methyl methacrylate catalyzed by ironII chloride/isophthalic acid system. Macromolecules 2000, 33, 8233-8238. [CrossRef]

94. Ding, M.Q.; Jiang, X.W.; Peng, J.Y.; Zhang, L.F.; Cheng, Z.P.; Zhu, X.L. An atom transfer radical polymerization system: Catalyzed by an iron catalyst in PEG-400. Green Chem. 2015, 17, 271-278. [CrossRef]

95. Liu, Y.; Xu, T.C.; Zhang, L.F.; Cheng, Z.P.; Zhu, X.L. Bulk AGET ATRP of methyl methacrylate using iron(iii) acetylacetonate as a catalyst. Polym. Chem. 2014, 5, 6804-6810. [CrossRef]

96. Mukumoto, K.; Wang, Y.; Matyjaszewski, K. Iron-based ICAR ATRP of styrene with ppm amounts of FeIIIBr 3 and 1,1'-azobis (cyclohexanecarbonitrile). ACS Macro Lett. 2012, 1, 599-602. [CrossRef]

97. Jakubowski, W.; Matyjaszewski, K. Activators regenerated by electron transfer for atom-transfer radical polymerization of (meth)acrylates and related block copolymers. Angew. Chem. 2006, 118, 4594-4598. [CrossRef]

98. Bai, L.J.; Zhang, L.F.; Zhang, Z.B.; Tu, Y.F.; Zhou, N.C.; Cheng, Z.P.; Zhu, X.L. Iron-mediated AGET ATRP of styrene in the presence of catalytic amounts of base. Macromolecules 2010, 43, 9283-9290. [CrossRef]

99. Jiang, H.J.; Zhang, L.F.; Pan, J.L.; Jiang, X.W.; Cheng, Z.P.; Zhu, X.L. Iron-mediated AGET ATRP of methyl methacrylate using metal wire as reducing agent. J. Polym. Sci. Part A 2012, 50, 2244-2253. [CrossRef]

(C) 2016 by the authors; licensee MDPI, Basel, Switzerland. This article is an open access article distributed under the terms and conditions of the Creative Commons by Attribution (CC-BY) license (http://creativecommons.org/licenses/by/4.0/). 